\title{
Wealth, health, and health services in rural Rajasthan
}

Abhijit Banerjee, Angus Deaton, and Esther Duflo

Poverty Action Lab Paper No. 8

May 2004

(c) Copyright 2004 Abhijit Banerjee, Angus Deaton, and Esther Duflo

Poverty Action Lab

TRANSLATING RESEARCH INTO ACTION 


\title{
Wealth, health, and health services in rural Rajasthan ${ }^{1}$
}

\author{
Abhijit Banerjee ${ }^{2}$ \\ Angus Deaton ${ }^{3}$ \\ Esther Duflo ${ }^{4}$
}

December 2003

\footnotetext{
${ }^{1}$ We thank Seva Mandir for their invaluable help in accessing their villages, and Vidhya Bhavan for hosting the research team. Special thanks go to Neelima Khetan, CEO of Seva Mandir, Hardy K Dewan, Organizing Secretary of Vidhya Bhawan, and Dr Renu and Dr Baxi from the health units of Seva Mandir. We thank Annie Duflo, Neeraj Negi, and Callie Scott, for their superb work in supervising the survey, and the entire health project team for their tireless effort. Callie Scott also supervised data entry and cleaning, and performed much of the data analysis underlying this paper. We are grateful to Lant Pritchett and Norbert Schady for excellent comments. We thank the Center for Health and Well Being at Princeton University, the John D. and Catherine T. MacArthur Foundation, the Alfred P. Sloan Foundation and the National Institutes of Health for funding for this research.

${ }^{2}$ Department of Economics, MIT

${ }^{3}$ Department of Economics and Woodrow Wilson School, Princeton University

${ }^{4}$ Department of economics, MIT
} 


\section{Introduction}

What are the determinants of the health and of well-being? Income and wealth are clearly part of the story, but does access to health-care have a large independent effect, as the advocates of more investment in health-care, such as the World Health Organization's Commission on Macroeconomics and Health (Commission on Macroeconomics and Health (2001)), have argued? This paper reports on a recent survey in a poor rural area of the state of Rajasthan in India intended to shed some light on this issue, where there was an attempt to use a set of interlocking surveys to collect data on health and economic status, as well as the public and private provision of health care.

\section{The Udaipur rural health survey}

We collected data between January, 2002 and August, 2003 in 100 hamlets in Udaipur district, Rajasthan Udaipur is one of the poorest districts of India, with a large tribal population and an unusually high level of female illiteracy (at the time of the 1991 census, only $5 \%$ of women were literate in rural Udaipur). The survey was conducted in collaboration with two local institutions: Seva Mandir, a NGO that works, among other things, on health in rural Udaipur and Vidhya Bhavan, a consortium of schools, teaching colleges and agricultural colleges, who supervised the administration of the survey. The sample frame consisted of all the hamlets in the 362 villages where Seva Mandir operates in at least one hamlet. ${ }^{5}$ The sample was stratified according to access to a road (out of the 100 hamlets, 50 hamlets are at least 500 meters away from a road). Hamlets within each stratum were

\footnotetext{
${ }^{5}$ A hamlet is a set of houses that are close together, share a community center, and constitutes a separate entity. A village is an administrative boundary. One to 15 hamlets constitute a village (the mean number of hamlets in a village is 5.6). Seva Mandir in general operates in the poorest hamlets within a given village.
} 
selected randomly, with a probability of being selected proportional to the hamlet population. We then selected 10 households in each of 100 hamlet using simple sampling, and all individuals were surveyed within each household.

The data collected include four components: a village survey, where we obtained a village census, a description of the village's physical infrastructure, and a list of health facilities commonly used by villagers (100 villages); a facility survey, where we collected detailed information on activities, types and cost of treatment, referrals, availability of medication and quality of physical infrastructure in all public facilities (143 facilities) serving the sample villages, all "modern" private facilities mentioned in the village surveys or in the household interviews (we have surveyed 85 facilities so far, but this survey is still going on), and a sample of the traditional healers mentioned in the village surveys (225 facilities were surveyed); a weekly visit to all public facilities serving the villages (143 facilities in total, with 49 visits per facility on average) where we checked whether the facility was open, and if so, who was present; and a household and individual survey, covering 5759 individuals in 1024 households. The data cover information on economic well being, integration in society, education, fertility history, perception of health and subjective well being, and experience with the health system (public and private), as well as a small array of direct measures of health (hemoglobin, blood pressure, weight and height, peak flow meter measurement).

\section{Health and Wealth in rural Udaipur}

The households in the Udaipur survey are poor, even by the standards of rural Rajasthan. Their average per capita household expenditure is 470 rupees, and more than 40 percent of the people live in households below the official poverty line, compared with only 13 percent in rural 
Rajasthan in the latest official counts for 1999-2000. Only 46 percent of adult (14 and older) males and 11 percent of adult females report themselves as literate. Of the 27 percent of adults with any education, three-quarters completed standard eight or less. The survey households have little in the way of household durable goods and only 21 percent have electricity. In terms of measures of health, 80 percent of adult women, and 27 percent of the adult men have hemoglobin levels below 12 grams by deciliters. 5 percent of adult women and 1 percent of adult men have hemoglobin levels below 8 grams per deciliters. Using a standard cutoff for anemia (11 g/dl for women, and $13 \mathrm{~g} / \mathrm{dl}$ for men), men are almost as likely (51\%) to be anemic as women (56\%) and older women are not less anemic than younger ones, suggesting that diet is a key factor. The average body mass index is 17.8 among adult men, and 18.1 among adult women. 93 percent of adult men and 88 percent of adult women have BMI less than 21, considered to be the cutoff for low nutrition in the US (Robert Fogel, 1997). Symptoms of disease are widespread, and adults (self) report a wide range of symptoms: a third report cold symptoms in the last 30 days, and 12 percent say the condition was serious. 33 percent reported fever (14 percent serious), 42 (20 serious) percent reported "body ache" 23 (7) percent reported fatigue, 14 (3) percent problems with vision, 42 (15) percent headaches, 33 (10) percent back aches, 23 (9) percent upper abdominal pain, 11 (4) percent had chest pains, and 11 (2) percent had experienced weight loss. Few people reported difficulties with personal care, such as bathing, dressing, or eating, but many reported difficulty with the physical activities that are required to earn a living in agriculture. Thirty percent or more would have difficulty walking 5 kilometers, drawing water from a well, or working unaided in the fields. Eighteen to twenty percent have difficulty squatting or standing up from a sitting position. 
Yet when asked to report their own health status, shown a ladder with 10 rungs, 62 percent place themselves on rungs 5 through 8 (more is better), and less than seven percent place themselves on one of the bottom two rungs. Unsurprisingly, older people report worse health. Also, women at all ages consistently report worse health than men, which appears to be a worldwide phenomenon. Nor do our life-satisfaction measures show any great dissatisfaction with life: on a five point scale, 46 percent take the middle value, and only 9 percent say their life makes them generally unhappy. Such results are similar to those for rich countries; for example, in the United States, more than a half of respondents report themselves as a three (quite happy) on a four-point scale, and 8.5 percent report themselves as unhappy or very unhappy. These people are presumably adapted to the sickness that they experience, in that they do not see themselves as particularly unhealthy nor, perhaps in consequence, unhappy. Yet they are not adapted in the same way to their financial status, which was also self-reported on a ten-rung ladder. Here the modal response was the bottom rung, and more than 70 percent of people live in households that are self-reported as living on the bottom three rungs.

What about the relation between health and wealth? The standard measure of economic status in India is household total per capita expenditure (PCE), which we collected using an abbreviated consumption questionnaire previously used by the National Sample Survey in the 1999-2000 survey. In table 1, we show self reported health, number of symptoms reported in the last 30 days, Body Mass Index, fraction of individuals with hemoglobin count below 12, peak flow meter, high blood pressure, low blood pressure, broken down by third of the per capita income distribution. Although the pattern is not always consistent across the groups, individuals etc., 
individuals in the lower third of the per capita income distribution have, on average, a lower level of self-reported health, lower body mass index, lower lung capacity, and are more likely to have a hemoglobin count below 12 than those in the upper third. Individual in the upper third report the most symptoms over the last 30 days, perhaps because they are more aware of their own health status; there is a long tradition in the Indian and developing country literature of better-off people reporting more sickness (see for example Christopher Murray and Lincoln C. Chen (1992) and Amartya K. Sen (2002)).

Figure 1, shows self-reported health as a function of age and gender comparing the bottom three deciles with the top three deciles. Self reported health is better in the higher deciles, though the effect is much stronger for men than for women, for whom there is little or no PCE gradient. The steeper gradient for men may be an indication that some of this relationship is driven by the effect of health on income, since we would observe such a relation if men earn more because they are stronger.

We investigate this further in Table 2, in which the self-reported health status is regressed on age, age-squared, and on measures of economic status. Our regressions showed that conditional on total household expenditure, neither health nor happiness was reduced by household size, so that we report regressions using total household expenditure rather than per capita household expenditure. We also show the results of using the household's own report of its financial status on a ten point scale; this measure is typically a better predictor of health and happiness than are expenditure measures. We also constructed a dummy for each adult indicating whether that person had earnings from work, and then regressed SRHS on each measure of economic status and its interaction with the worker dummy. As anticipated, the slope of the regression of health 
on economic status is higher for earners, by about a fifth for total household expenditure, and by a factor of two for the self-reported economic status measure. Column 2 shows the same regression with an indicator for having a hemoglobin level below $12 \mathrm{~g} / \mathrm{dl}$ as the dependent variable. In both cases, we also find the interaction between the income earner dummy and the household welfare status to be negative. These findings are consistent with the idea that at least some of the gradient comes from the effects of health on earnings, although they could also indicate that the nutrition and health inputs received by workers is more income elastic than that of non-workers. The last column of the table show parallel regressions with happiness rather than health as the dependent variable. A concern with these subjective variables is that there is a personality based (and reality-free) component that is common to both the happiness and the health measure, and which could be different for workers and non-workers. But these regressions, unlike those for SRHS or anemia, show no effects of the interaction term; there appears to be some suggestive evidence of a feedback from health to earnings, but not from happiness to earnings

\section{Health-care and health in rural Udaipur}

The combination of the public facility survey, a private facility survey, and the household survey casts light on the state of public and private health care provision in Udaipur district and their place in people's lives.. The picture is bleak. Starting with the public health facility surveys, the weekly absenteeism survey reveals that, on average, $45 \%$ of medical personnel is absent in subcenters and aid posts, and $36 \%$ are absent in the (larger) Primary Health Centers and Community Health 
Centers. ${ }^{6}$ These high rates of absences are not due to staff attending patients; whenever the nurse was absent from a subcenter, we made sure to look for her in the community. Since subcenters are often staffed by only one nurse, this high absenteeism means that these facilities are often closed: we found the subcenters closed $56 \%$ of the time during regular opening hours. Only in $12 \%$ of the cases was she to be found in the one of the village served by her subcenter. The situation does not seem to be specific to Udaipur: these results are similar to the absenteeism rate found in nationally representative surveys in India and Bangladesh (Nazmul Chaudhury and Jeffrey Hammer (2003), Chaudhury, Hammer, Michael Kremer, Kartik Muralidharan and Halsey Rogers (2003)). The weekly survey allows us to assess whether there is any pattern in center opening. For each center, we ran a regression of the fraction of personnel missing on dummies for each day of the week, time of the day, and seasonal dummies. We find that the day of the week dummies are significant at the $5 \%$ level in only $7 \%$ of the regressions, and the time of the day dummies are significant only in $10 \%$ of the regressions. The public facilities are thus open infrequently and unpredictably, leaving people to guess whether it is worth their while walking for over half an hour to cover the 1.4 miles that separate the average village in our sample from the closest public health facility.

Faced with this situation, do households forgo the consumption of health care? Far from it: Households spend a considerable fraction of their monthly budget on health care. In the expenditure survey, households report spending $7.3 \%$ of their budget on health care. Households in the top third of the per capita income distribution spend $11 \%$ of the budget on health care. Visits to public facilities are generally not free (the households spend on average 110 rupees when they visit a health

\footnotetext{
${ }^{6}$ A subcenter serves 3600 individuals and is usually staffed by one nurse. A primary health center serves 48000 individuals and has on average 5.8 medical personnel appointed, including 1.5 doctors.
} 
facility) even though medicines and services are supposed to be free, when they are "available". Even those who are officially designated as "below the poverty line", who are entitled to completely free care, end up paying only $40 \%$ less in public facilities than others. Visits to traditional healers ("bhopas") account for $19 \%$ of the visits and $12 \%$ of the health expenditure of the average household. Poorer households are more likely to visit the bhopas than richer household (27\% of the visits and $19 \%$ of the average monthly health expenditure), especially in villages where the public health facilities is closed the most often: in the villages served by the third of facilities that are closed the most often, $29 \%$ of the health visits of the poor are to bhopas (as against $18 \%$ in villages served by facilities that are the most open). Irrespective of whether the public facility serving the village is mostly closed or not, visits to other private providers accounts for $57 \%$ of the visits and $65 \%$ of the costs.

Health personnel in the private sector are often untrained and largely unregulated, even we leave out the bhopas. According to their own report, $41 \%$ of those who called themselves "doctors" do not have a medical degree. $18 \%$ have no medical training whatsoever. $17 \%$ have not graduated from high school. ${ }^{7}$ Given the symptoms reported by the villagers, the treatment received in these facilities appears rather heterodox: in $68 \%$ of the visits to a private facility the patient is given an injection; in $12 \%$ of the visits he is given a drip. A test is performed in only $3 \%$ of the visits. In public facilities, they are somewhat less likely to get an injection or a drip (32\% and $6 \%$ respectively) but no more likely to be tested.

These data paints a fairly bleak picture: villagers' health is poor; the quality of the public service is abysmal; private providers unregulated and for the most part unqualified provide the bulk of health 
care in the area. Having low quality public facilities is correlated with some direct health measures: Lung capacity and body mass index are lower where the facilities are worse, after controlling for household per capita monthly expenditure, distance from the road, age, and gender;. Yet, as we have seen for the self reported health status, villagers not only do not perceive their health as particularly bad, but they seem pretty content with what they are getting. $81 \%$ report that their last visit to a private facility made them feel better, and $75 \%$ report that their last visit to a public facility made them feel better. Self reported health and well being measures, as well as the number of symptoms reported in the last month, appear to be uncorrelated with the quality of the public facilities. The quality of the health services, may impact health but does not seem to impact people's perception of their own health or of the healthcare system.

\section{REFERENCES}

Chaudhury, Nazmul and Jeffrey Hammer "Ghost Doctors: Absenteeism in Bangladeshi Health Facilities” MIMEO, Development Research Group, 2003, World Bank

Chaudhury, Nazmul, Jeffrey Hammer, Michael Kremer, Kartik Muralidharan and Halsey

Rogers, "Teachers and Health care providers Absenteeism: A multi-country study, MIMEO, Development Research Group”, 2003, World Bank

Commission on Macroeconomics and Health, Macroeconomics and health: investing in health for economic development, Geneva, 2001, World Health Organization.

Das, Jishnu, "Three essays on the provision and use of services in low income countries", 2001, Ph.D. dissertation, Harvard University.

Fogel, Robert W., "New findings on secular trends in nutrition and mortality: some implications for

${ }^{7}$ Based on an incomplete sample of 72 doctors. 
population theory," in Oded Stark and Mark Rosenzweig, eds., Handbook of Population and Family Economics, Amsterdam, Elsevier,1997, 433-81.

Murray, Christopher J. L.,. and Lincoln C. Chen, "Understanding morbidity change," Population and Development Review, 1992, 18(3) 481-503.

Sen, Amartya K., "Health: perception versus observation,” British Medical Journal, 2002 324, 8601. 
Table 1: Selected health indicators, by position in the per capita monthly expenditure distribution

\begin{tabular}{|c|c|c|c|c|c|c|c|c|}
\hline group & $\begin{array}{l}\text { reported } \\
\text { health } \\
\text { status }\end{array}$ & $\begin{array}{l}\text { No. of symptoms } \\
\text { self reported in last } \\
30 \text { days }\end{array}$ & BMI & $\begin{array}{l}\text { hemoglobin below } \\
12 \mathrm{~g} / \mathrm{dl}\end{array}$ & $\begin{array}{l}\text { peak flow meter } \\
\text { reading }\end{array}$ & $\begin{array}{l}\text { high blood } \\
\text { pressure }\end{array}$ & \multicolumn{2}{|c|}{ low blood pressure } \\
\hline bottom third & & 3.89 & 17.85 & 0.57 & 314.76 & & 0.17 & 0.06 \\
\hline middle third & & 3.73 & 17.83 & 0.59 & 317.67 & & 0.15 & 0.08 \\
\hline top third & & 3.96 & 18.31 & 0.51 & 316.39 & & 0.20 & 0.09 \\
\hline
\end{tabular}

Note:

Means based on data collected by the author from 1024 households. See text for survey and variable description 
Table 2: Health, happiness, and economic status

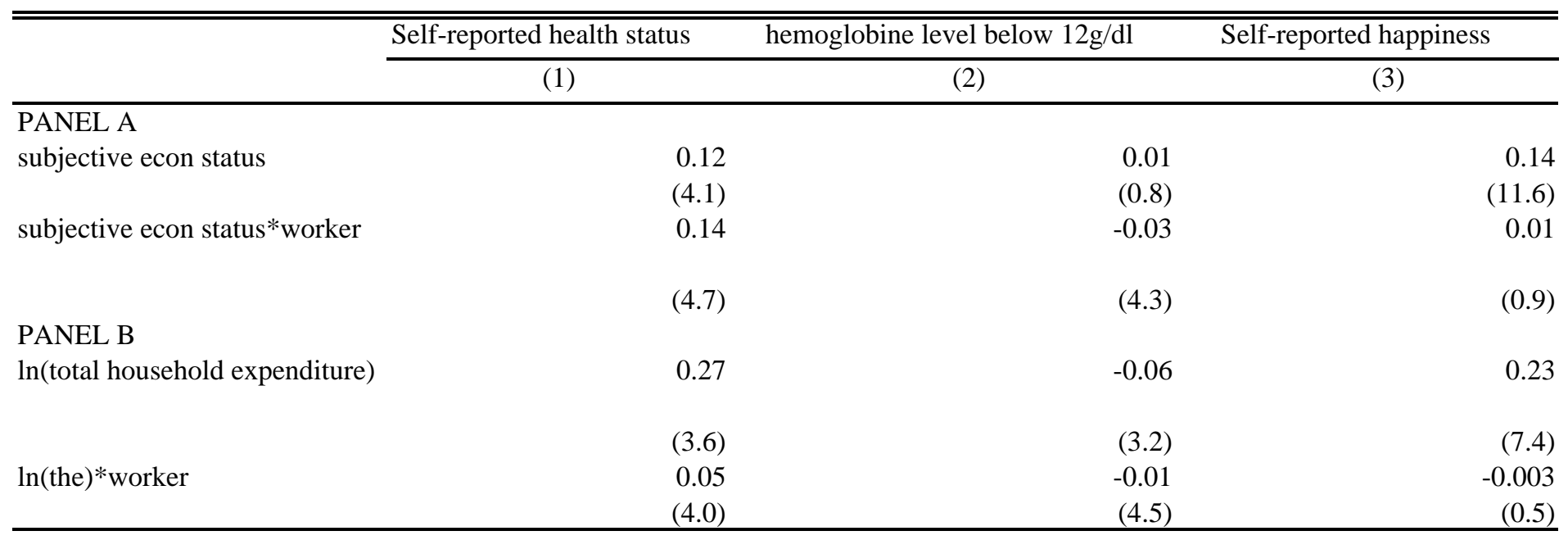

Notes:

Regressions also include age and age squared.

The absolute t-statistic is reported in parentheses below the coefficient. 


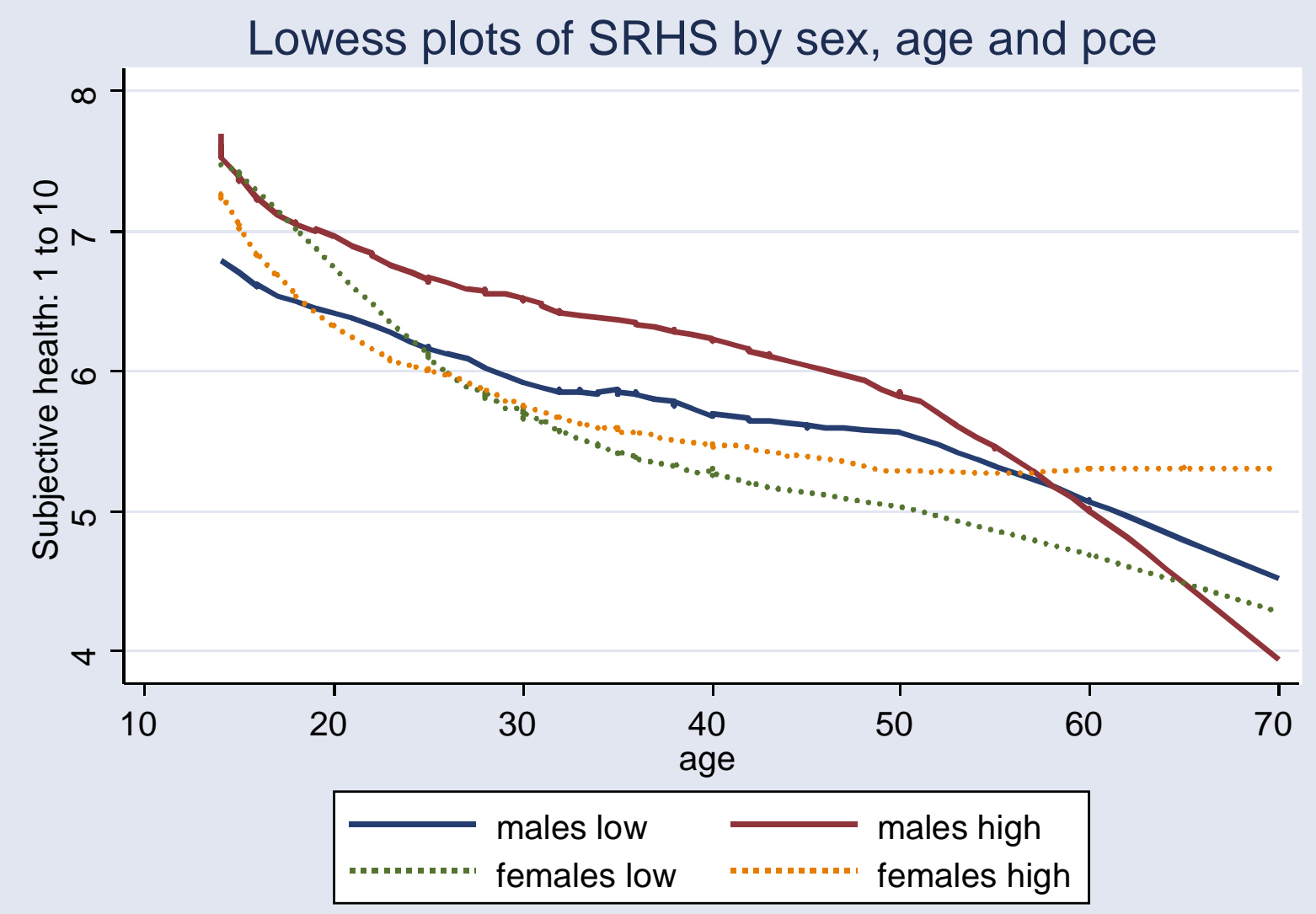

